\title{
Books by Q.H. Vuong at UC Berkeley Library
}

\author{
UCB Library Catalog
}

Access:

March 2, 2021

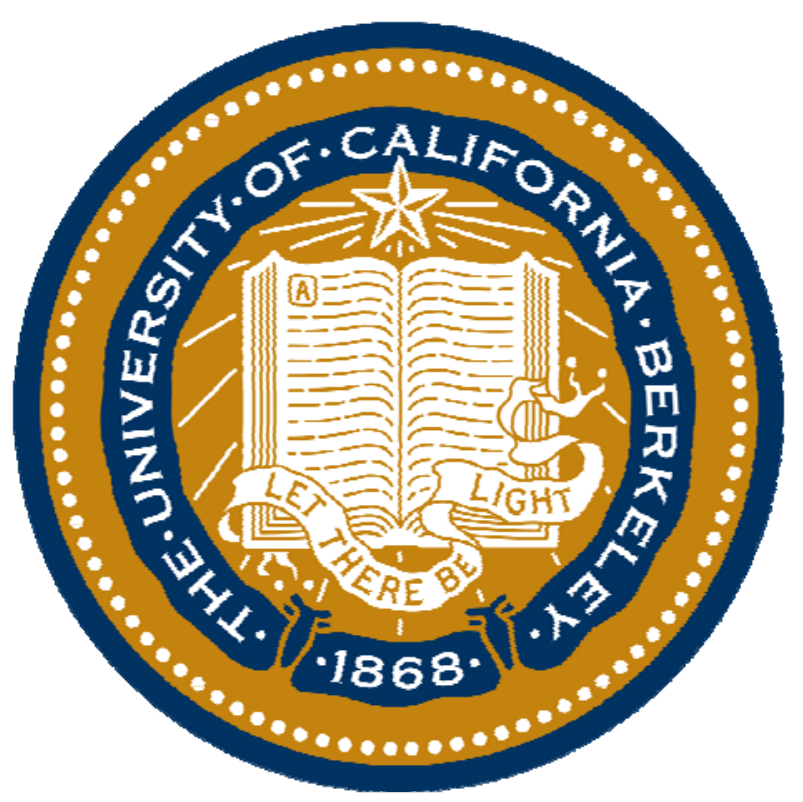

University of California at Berkeley

Querying URL:

https://eds.b.ebscohost.com/eds/results?vid=1\&sid=0cc311c1-c563-40d5-807e-

fde4e0b212dc\%40pdc-v-

sessmgr03\&bquery=Quan\%2bHoang\%2bVuong\&bdata=JnR5cGU9MCZzZWFyY2hNb2RIPUFuZC ZzaXRIPWVkcy1saXZI

The search results in two books by Q.H. Vuong and other co-authors. Their brief information and bibliographic details are provided in what follows.

\section{Kinh tế Việt Nam: Thăng trầm và đột phá}

LCCN: 2009335322

OCLC: 460941054

Accession Number: ucb.b17678589 
First author: Phạm Minh Chính

Location: Main (Gardner) Stacks; Call number: HC444 .P517 2009, HC444 .P446 2009

URL: https://eds.b.ebscohost.com/eds/detail/detail?vid=0\&sid=15a54c1e-310e-4503-bc1c-

dd67cd6c423d\%40sessionmgr102\&bdata=JnNpdGU9ZWRzLWxpdmU\%3d\#AN=ucb.b17678589

$\& d b=c a t 04202 a$

2. Bằng chứng cuộc sống: Suy nghĩ về phát triển bền vững Việt Nam

OCLC: 933496759

Accession Number: ucb.b23986721

First author: Bạch Ngọc Chiến

Location: Main (Gardner) Stacks; Call number: HC444.Z9 E523 2015

URL: https://eds.b.ebscohost.com/eds/detail/detail?vid=0\&sid=4f691b5d-bde9-4f8d-81efa3cf472192d6\%40pdc-v-

sessmgr02\&bdata=JnNpdGU9ZWRzLWxpdmU\%3d\#AN=ucb.b23986721\&db=cat04202a 


\section{Kinh tê Việt Nam : thăng trâm và đột phá / Phạm Minh Chính, Vương Quân Hoàng.}

Language:

Authors:

Publication

Information:

Publication Date:

Physical

Description:

Publication Type: Book

Document Type: Bibliographies; Non-fiction

Subject Terms: $\quad$ Economic development -- Vietnam -- History

Abstract:

Notes:

Other Authors:

LCCN:

OCLC:

Accession Number:
Structural adjustment (Economic policy) -- Vietnam -- History

Vietnam -- Economic conditions -- 1975-

Vietnamese

Phạm, Minh Chính

Hà Nội : Nhà xuát bản Chính trị quốc gia, 2009.

2009

xxx, 554 p. : ill. ; $23 \mathrm{~cm}$.

Summary: Portraits of strategy and development of economic in Vietnam.

Includes bibliographical references (p. 539-549) and index.

Vương, Quân Hoàng

2009335322

460941054

ucb.b17678589

\begin{tabular}{|l|l|l|}
\hline Location & Call No. & Status \\
\hline Main (Gardner) Stacks & HC444.P517 2009 & AVAILABLE \\
\hline Main (Gardner) Stacks & HC444 .P446 2009 & AVAILABLE \\
\hline Show Less & & \\
\hline
\end{tabular}




\section{Bằng chứng cuộc sống : suy nghĩ về phát triển bền vững Việt $\mathrm{Nam} / \mathrm{Bạch} \mathrm{Ngọc} \mathrm{Chiến,}$ Vương Quân Hoàng.}

Language:

Authors:

Publication

Information:

Publication Date:

Physical

Description:

Publication Type:

Document Type:

Subject Terms:
Vietnamese

Bạch, Ngọc Chiến, author

Hà Nội : Nhà xuất bản Chính trị quốc gia - Sự thật, 2015.

2015

255, a-w pages : illustrations (some color), charts ; $22 \mathrm{~cm}$

Book

Bibliographies; Non-fiction

Sustainable development -- Vietnam

Economic policy

Sustainable development

Vietnam -- Economic policy -- 1975-

Vietnam

Includes bibliographical references (pages A-P) and index.

Vương, Quân Hoàng, author

933496759

Accession Number: ucb.b23986721

\begin{tabular}{|l|l|l|}
\hline Location & Call No. & \multicolumn{1}{l|}{ Status } \\
\hline Main (Gardner) Stacks & HC444.Z9 E523 2015 & AVAILABLE \\
\hline
\end{tabular}

† Similar Books 


\section{Bibliography}

[1] Phạm Minh Chính, Vương Quân Hoàng. (2009). Kinh tế Việt Nam: Thăng trầm và Đột phá. Nxb Chính trị Quốc gia, Hà Nội.

[2] Bạch Ngọc Chiến, Vương Quân Hoàng. (2015). Bằng chứng cuộc sống: Suy nghĩ về phát triển bền vững Việt Nam. Nxb Chính trị Quốc gia, Hà Nội. 